\title{
Excess injury mortality among smokers: a neglected tobacco hazard
}

\author{
C P Wen, S P Tsai, T Y Cheng, H T Chan, W S I Chung, C J Chen
}

Tobacco Control 2005;14(Suppl I):i28-i32. doi: 10.1136/tc.2003.005629

See end of article for authors' affiliations

Correspondence to: Chi Pang Wen, Division of Health Policy Research, National Health Research Institutes, Taipei, Taiwan cwengood@nhri.org.tw
Objective: To assess the mortality risks from injuries for smokers and ex-smokers and to quantify the mortality burden of smoking from injury in Taiwan.

Methods: Smokers' (and ex-smokers') mortality risks from injuries were compared with that of nonsmokers in a merged cohort from Taiwan. A total of 64319 male subjects were followed up for 12-18 years. Relative risks (RR) (adjusted for age and alcohol use) and $95 \%$ confidence intervals (CI) for cause specific injury deaths were calculated using the Cox proportional hazard model. Relative risks of injury mortality were also calculated to assess the presence of dose-response relations with daily smoking quantity.

Results: Alcohol use adjusted relative mortality risks for all injuries (RR 1.69, 95\% Cl 1.39 to 2.05) including those from motor vehicle accidents (RR 1.88, 95\% Cl 1.44 to 2.45 ) and non-motor vehicle accidents (RR 1.48, 95\% Cl 1.11 to 1.99 ) were significantly higher for smokers than non-smokers. Mortality was also increased for most subtypes of non-motor vehicle injuries including falls, fires, and job related injuries. Furthermore, these increases were dose dependent, with the heaviest smokers having the highest risk and the lightest smokers the lowest risk, and ex-smokers, no increase. In 2001, over one fifth $(23 \%)$ of all male injury deaths in Taiwan was associated with smoking.

Conclusion: This study demonstrated the significant association between fatal injuries and smoking. This relation adds further weight to smoking cessation campaigns.
$\mathrm{T}$ he relation between smoking and injury was not addressed in two large American Cancer Society studies (CPS-I and CPS-II), ${ }^{1}$ in the Surgeon General's reports on smoking, ${ }^{2}{ }^{3}$ or in the World Health Organization's calculation of global deaths attributed to tobacco use. ${ }^{4}$ The US Centers for Disease Control and Prevention did not include injury in their calculation of smoking attributable mortality (SAM), except for fire related deaths. ${ }^{5}$ However, numerous reports have discussed the propensity of smokers to have higher injury risks from both motor vehicle and non-motor vehicle injuries, ${ }^{6-14}$ and only recently has this topic been the subject of review and meta-analysis. ${ }^{15}{ }^{16}$ Leistikow et al reviewed 263 studies published between 1966 and 1995 and found that smokers had an injury relative risk (RR) of 1.61 (95\% confidence interval (CI) 1.44 to 1.81 ) over non-smokers. ${ }^{16}$ The relation between smoking and injury was found to be significant, consistent, and showed a linear dose-response pattern. Based on an analysis of a US national cohort study between 1990 and 1995, smoking was concluded to be "a leading contributor to injuries and injury may be a leading burden from smoking, both nationally and globally."17

Nevertheless, the smoking and injury issue has received little attention in tobacco control policy consideration. ${ }^{3}$ This could be due to the recentness of published studies, and concerns that some of those studies might not have accounted for confounders such as alcohol use. Others could have dismissed its importance by noting that smokers are more willing to take risks and thus are more injury prone. ${ }^{15}$ In this study, we use two existing prospective study cohorts from Taiwan, consisting of white collar and blue collar populations, to assess the relation between smoking and fatal injury including injury subtypes that have not been fully explored in the literature. Whether the reported relation between smoking and injury is applicable to Taiwan or not has profound public health implications.

\section{METHODS}

This study was based on an analysis of a large cohort comprised of two subcohorts: one consisting of 71361 individuals, mostly civil servants and teachers, who took the government sponsored annual physical examination programme initiated in $1989^{18}$; and the other consisting of 66161 individuals residing in both rural and urban townships from a community based follow up study, started in 1982. ${ }^{19}$ Each of the cohorts consisted of both sexes, but the analysis was limited to males 18 years of age and older $(\mathrm{n}=64319)$, as extremely low smoking rates among females yielded too few deaths for analysis. Vital status as of 31 December 2001 and causes of death information were ascertained through matches between the cohort members and a computerised national causes of death database. Causes of death were classified according to the ninth revision of the International classification of diseases (ICD-9). The increased mortality risk for smokers in this cohort has been reported elsewhere. ${ }^{20}$ We categorised all injury deaths (ICD-9 E800-E949) as MVA (motor vehicle accidents) (E 810E829) and N-MVA (non-motor vehicle accidents) (E 859E929). Within N-MVA, job related injuries were defined as those in ICD codes E916-E925, as many of those injuries were more likely to be associated with occupational than nonoccupational activities.

Smoking and drinking histories of the studied subjects were obtained at the time of recruitment, among other lifestyle risk factors, from a written self administered questionnaire. Current smokers were those who stated they

\footnotetext{
Abbreviations: CDC, Centers for Disease Control and Prevention; $\mathrm{Cl}$, confidence interval; CPS, cancer prevention study; ICD, International classification of disease; MVA, motor vehicle accidents; NHIS, National Health Interview Survey; N-MVA, non-motor vehicles accidents; RR, relative risk; SAF, smoking attributable fraction; SAM, smoking attributable mortality
} 
smoked daily. Virtually all $(99.8 \%)$ current smokers in this study had smoked 100 or more cigarettes in their lifetime. Ex-smokers were those who smoked daily in the past but had quit. Never-smokers were primarily those who never smoked with only few $(0.2 \%)$ who smoked less than 100 cigarettes in their lifetime. Drinkers were those who used alcohol (that is, wine, beer, or hard liquor) on a regular basis. Those who indicated they were occasional or party drinkers were not counted as drinkers in this study. As quantitative drinking data were only available for a portion of the cohort, the risks associated with different intensities of alcohol use were not analysed. Typical drinking patterns in Taiwan are different from those in Western countries. Relatively few Taiwanese are chronic alcoholics, and drinking problems stem more from binge drinking during social occasions. ${ }^{21}$

Relative risks (RR) and 95\% confidence intervals (CI) for cause specific mortality were estimated using the Cox proportional hazard model, comparing smokers with nonsmokers and adjusting for age and alcohol use. A similar analysis was also conducted adjusting for education (junior high school or lower, senior high school, and college and above), as a proxy for socioeconomic status or occupational group, as well as age and alcohol use. This analysis was conducted to assess the extent of the smoking-injury association that may be confounded by socioeconomic status differences between smokers and non-smokers. Smoking attributable fraction (SAF), as developed by the US Centers for Disease Control and Prevention (CDC), ${ }^{22}$ was applied, which was based on the following formula: $\mathrm{SAF}=\mathrm{P}(\mathrm{RR}-1)$ / $[\mathrm{P}(\mathrm{RR}-1)+1]$, where $\mathrm{P}=$ prevalence of adult smoking rate, and $\mathrm{RR}=$ relative risks of specific causes of injury deaths among adult smokers compared with non-smokers.

SAM from injury is the product of SAF and mortality-that is, SAF times the national number of adult deaths from a specific cause of injury. It is to be noted that SAM from injury presented in this study represents only the estimated number of fatal injuries that could be associated with smoking.

\section{RESULTS}

Characteristics of the cohort are presented in table 1 . The study cohort consisted of 64319 males, with 40.2\% identified as current smokers and $10.1 \%$ as ex-smokers. The average age of the cohort at recruitment was 46.5 years. A total of 687681 person years were observed. The proportion of the cohort who classified themselves as a regular alcohol users were $14.9 \%$ as a whole, but more than three times more smokers indicated they were regular drinkers $(24.0 \%)$ than non-smokers $(6.9 \%)$.

Age and alcohol use adjusted relative risks for smokers compared to non-smokers were increased significantly for all injury deaths (RR 1.69, 95\% CI 1.39 to 2.05), or its components, MVA (RR 1.88, 95\% CI 1.44 to 2.45) and NMVA (RR 1.48, 95\% CI 1.11 to 1.99) (table 2). Among the subtypes of N-MVA, the increased relative risks of fall (RR
$1.95,95 \%$ CI 1.09 to 3.48 ) and job related accidents (RR 2.91, $95 \%$ CI 1.004 to 8.42 ) were significant. Mortality risks were also increased for fire, drowning, and suicide, but the increases were not significant. For ex-smokers, none of the relative risks reached significance, although some of the risks, such as dying from fall, drowning, and suicide, were increased above the null.

The above analysis was repeated by further adjustment for educational levels (middle school or lower, high school, and college or higher) to assess the impact of socioeconomic status as a potential confounding factor on injury risk. Although the pattern of cause specific injury mortality was similar to that exhibited in table 2, the addition of education to the alcohol adjusted RRs for smoking were generally lower than those adjusted for alcohol only, 24\% lower for all injuries, 22\% for MVA, and 27\% for N-MVA. Nevertheless, the significance of the increase of smokers remained for all injuries.

When grouped by smoking intensity (number of cigarettes smoked per day) a significant monotonic dose-response relation was seen for all injuries, MVA, N-MVA, fall, and job related injuries (table 3 ), with the heaviest smokers having the highest risk, the lightest smokers the lowest risk, and exsmokers, no increase.

Based on relative mortality risks derived above and the observed smoking prevalence among males from the National Health Interview Survey (NHIS) in Taiwan, ${ }^{23}$ SAFs for MVA and N-MVA in 2001 were calculated to be $29.3 \%$ and $17.6 \%$, respectively. Altogether, SAF was $24.0 \%$ for all injury deaths in males. SAM, based on CDC method, ${ }^{22}$ from MVA in 2001 was 916 deaths and from N-MVA, 569. The combined number of 1485 deaths constituted 23\% of all injury deaths among male adults in Taiwan.

\section{DISCUSSION}

In this study, smoking has been associated with increased injury deaths among males in Taiwan, being a factor in at least one out of every five such deaths. The association persisted after educational levels were considered. Studies linking smoking and injuries have, so far, been limited to European and North American populations. ${ }^{15-17}$ The magnitude of relative risks for all injuries in this Taiwan study (RR 1.69) was similar to the one that combined all white populations (RR 1.61), ${ }^{16}$ by reviewing 263 studies. Injury deaths in Taiwan had been ranked as the second leading cause of death for males of all ages for most of the last 30 years, and the leading cause for those younger than 60 years of age. ${ }^{24}$ With its obvious public health implications, the link between smoking and injury has become all the more important.

Reservations about attributing accidental injuries to smoking as an independent risk factor have stemmed from the concern that studies may not have adjusted for drinking ${ }^{15-17}$ or socioeconomic status. ${ }^{17}$ The association

\begin{tabular}{|c|c|c|c|c|}
\hline & Total & Smoker & Ex-smoker & Non-smoker \\
\hline Number of subjects (\%) & $64319(100.0)$ & $25848(40.2)$ & $6515(10.1)$ & $31956(49.7)$ \\
\hline Person years & 687681 & 290076 & 62785 & 334821 \\
\hline Mean (SD) age (years) & $46.5(11.8)$ & $47.8(12.0)$ & 49.0 (11.9) & $45.0(11.3)$ \\
\hline \multicolumn{5}{|l|}{ Drinking } \\
\hline Number & 9604 & 6212 & 1173 & 2219 \\
\hline Prevalence (\%) & 14.9 & 24.0 & 18.0 & 6.9 \\
\hline \multicolumn{5}{|l|}{ Number of death } \\
\hline All causes & 5346 & 3393 & 348 & 1605 \\
\hline Non-intentional injuries & 523 & 333 & 24 & 166 \\
\hline
\end{tabular}


Table 2 Age and alcohol use adjusted relative risks (RR) of injury for male current smokers and ex-smokers

\begin{tabular}{|c|c|c|c|c|c|c|c|c|}
\hline \multirow[b]{2}{*}{ Cause of deaths (ICD 9 codes) } & \multicolumn{2}{|c|}{ Non-smokers } & \multicolumn{3}{|c|}{ Current smokers } & \multicolumn{3}{|c|}{ Ex-smokers } \\
\hline & $\mathbf{n}$ & $\mathbf{R R}$ & $\mathbf{n}$ & $\mathbf{R R}$ & $95 \% \mathrm{Cl}$ & $\mathbf{n}$ & $\mathbf{R R}$ & $95 \% \mathrm{Cl}$ \\
\hline All non-intentional injuries (E800-E949) & 166 & 1.00 & 333 & 1.69 & 1.39 to 2.05 & 24 & 0.64 & 0.41 to 0.995 \\
\hline MVA (E810-E829) & 85 & 1.00 & 197 & 1.88 & 1.44 to 2.45 & 10 & 0.48 & 0.24 to 0.93 \\
\hline NMVA (E850-E929) & 78 & 1.00 & 129 & 1.48 & 1.11 to 1.99 & 13 & 0.80 & 0.44 to 1.47 \\
\hline Fall (E880-E888) & 18 & 1.00 & 38 & 1.95 & 1.09 to 3.48 & 4 & 1.24 & 0.40 to 3.82 \\
\hline Fire (E890-E899) & 2 & 1.00 & 5 & 1.78 & 0.32 to 9.77 & 1 & - & - \\
\hline Drowning (E910-E915) & 16 & 1.00 & 19 & 1.00 & 0.50 to 2.01 & 5 & 1.54 & 0.53 to 4.50 \\
\hline Job related accidents (E916-E925) & 5 & 1.00 & 13 & 2.91 & 1.004 to 8.42 & 0 & - & \\
\hline Suicide (E950-E959) & 15 & 1.00 & 26 & 1.37 & 0.70 to 2.68 & 5 & 2.12 & 0.72 to 6.20 \\
\hline
\end{tabular}

RR not shown for causes of death $<2$.

$\mathrm{Cl}$, confidence interval

between smoking and drinking is well established. ${ }^{25} 26$ Our study found that a smoker's risk for injury remained elevated even after adjusting for alcohol use. However, injury mortality risks were lower after additional adjustments were made for education, a proxy for socioeconomic status.

One suggested mechanism for the strong association is that smokers suffer from "nicotine withdrawal" symptoms, such as irritation and listlessness, most of the time when not smoking. ${ }^{27}$ In UK, increased workplace accidents were recorded on the "No smoking day" every year between 1987 and 1996, when large number of smokers attempted to abstain from smoking on those days. ${ }^{28}$ Some have described smokers as having "performance decrements" while abstaining, as their mood and cognitive performance deteriorates within a few hours of beginning to abstain. ${ }^{29}$ Smoking while driving a car has been shown to increase the number of accidents and mortality risk. ${ }^{30-32}$ Distractions, lapses of manual dexterity, or blurred vision from smoke have all been suggested as responsible mechanisms of increased injury. ${ }^{33}$ In Taiwan, the smoker's injury risks could further be exacerbated by riding motorcycles, since more than half of the male adult population in Taiwan owns motorcycles ${ }^{34}$ and $60 \%$ of all MVA mortality involved motorcycles. ${ }^{35}$ Thus, it can be argued that the smoking behaviour of motorcyclists may have played an important role. In fact, it is not uncommon to sight "smoking cyclists" on the streets in Taiwan.

Another contributing factor is the potential for smokers to inadvertently start fires. Burning cigarettes are a fire hazard, especially near flammable objects. Smoking is the leading cause of deaths from residential fires in the USA, and nearly one third of deaths by burning were caused by cigarettes. ${ }^{15}$ With an average of 200 deaths a year from fire in Taiwan, ${ }^{24}$ approximately 1.3 such deaths a week can be associated with cigarette smoking.
Impaired ability to recover from injuries in smokers may add to the death toll. This includes poor wound healing, delayed bone union, decreased blood flow, diminished tissue oxygenation, diminished immunity, increased wound infections, and more severe pulmonary complications among injured smokers. ${ }^{15}{ }^{16}$ All of these factors increase morbidity and make complications more serious in smokers, leading to increased mortality. For this reason, surgeons prefer or even require smokers to quit smoking weeks before elective surgery. ${ }^{16} 36$

Smokers may have a higher propensity for risk taking, ${ }^{37}$ by not wearing a seatbelt in cars, $^{32}$ having more traffic violations, ${ }^{31}$ or driving while drunk. ${ }^{30}$ In addition, workers who smoke cause more workplace injuries than nonsmokers. ${ }^{63} 38$ Our data also suggest Taiwanese smokers have increased job related injuries.

When smokers quit in Taiwan, their excess risks for accidental deaths seem to disappear. This reduction of injury risks almost immediately after quitting has been reported, ${ }^{39} 40$ and is in sharp contrast to the much slower reduction of exsmoker's risks from other causes, such as coronary heart diseases or lung cancer. ${ }^{41}$ In a number of randomised trials in which smokers were randomised to smoking cessation programmes, the association between smoking and injury emerged. ${ }^{39}{ }^{42}$ Thus, it is particularly encouraging for promoting smoking cessation to reduce fatal injuries.

Historically, smokers have claimed their right to smoke as long as smoking does not affect others. In this regard, societal concern has been mainly limited to the risk of non-smokers from exposure to second hand smoke, particularly when young children were affected. However, the fact that nonsmokers may be at increased risk for various injuries (for example, fire, MVA, and job related accidents) caused by smokers has not been widely recognised. The right of

Table 3 Age and alcohol use adjusted relative risks (RR) of injury for current smokers by daily smoking quantity

\begin{tabular}{|c|c|c|c|c|c|c|c|c|c|c|c|c|}
\hline \multirow[b]{2}{*}{ Cause of deaths (ICD 9 codes) } & \multicolumn{2}{|c|}{ Non-smokers } & \multicolumn{3}{|c|}{$\leqslant 10$ cigs/day } & \multicolumn{3}{|c|}{$11-20$ cigs/day } & \multicolumn{3}{|c|}{$>20$ cigs $/$ day } & \multirow[b]{2}{*}{ p Value* } \\
\hline & $\mathbf{n}$ & RR & n & RR & $95 \% \mathrm{Cl}$ & $\mathbf{n}$ & RR & $95 \% \mathrm{Cl}$ & $\mathbf{n}$ & RR & $95 \% \mathrm{Cl}$ & \\
\hline $\begin{array}{l}\text { All non-intentional injuries } \\
\text { (E800-E949) }\end{array}$ & 166 & 1.00 & 87 & 1.37 & 1.05 to 1.78 & 189 & 1.76 & 1.41 to 2.20 & 38 & 2.27 & 1.54 to 3.34 & $<0.01$ \\
\hline MVA (E810-E829) & 85 & 1.00 & 52 & 1.54 & 1.08 to 2.19 & 115 & 2.01 & 1.49 to 2.72 & 20 & 1.95 & 1.14 to 3.34 & $<0.01$ \\
\hline NMVA (E850-E929) & 78 & 1.00 & 32 & 1.11 & 0.73 to 1.69 & 72 & 1.52 & 1.09 to 2.14 & 17 & 2.58 & 1.47 to 4.52 & $<0.01$ \\
\hline Fall (E880-E888) & 18 & 1.00 & 12 & 1.92 & 0.91 to 4.05 & 20 & 1.83 & 0.93 to 3.60 & 5 & 4.20 & 1.50 to 11.75 & 0.01 \\
\hline Fire (E890-E899) & 2 & 1.00 & 0 & - & & 3 & 1.47 & 0.22 to 9.84 & 1 & - & - & - \\
\hline Drowning (E910-E915) & 16 & 1.00 & 7 & 1.00 & 0.40 to 2.51 & 6 & 0.58 & 0.21 to 1.55 & 4 & 2.23 & 0.67 to 7.35 & 0.99 \\
\hline $\begin{array}{l}\text { Job related accidents } \\
\text { (E916-E925) }\end{array}$ & 5 & 1.00 & 2 & 1.38 & 0.26 to 7.19 & 8 & 3.36 & 1.03 to 10.97 & 2 & 5.72 & 0.95 to 34.54 & 0.01 \\
\hline Suicide (E950-E959) & 15 & 1.00 & 4 & 0.72 & 0.24 to 2.21 & 16 & 1.64 & 0.77 to 3.50 & 2 & 1.77 & 0.39 to 8.10 & 0.22 \\
\hline
\end{tabular}




\section{What this paper adds}

Smokers have higher injury rates than non-smokers, even when alcohol and social class are considered. In Taiwan there are significant relations between dose (daily smoking amount) and response (injury death). Over one fifth (23\%) of all male injury deaths in Taiwan were associated with smoking. Smokers have more motor vehicle accidents in Taiwan, partly because many smoke while riding motorcycles.

smokers to smoke should be qualified accordingly, as we begin to realise the potential effect on others' lives and property. Currently like drinking, smoking remains a private pursuit unless others are hurt or killed. When more of this is understood and communicated widely about the association between smoking and injuries, society may view smoking differently.

Suicide was increased among smokers in Taiwan, but the small sample size may have limited its significance. Mechanisms to explain the increased suicide risks in smokers are complex, as situations differ. ${ }^{43}{ }^{44}$ The relation between smoking and suicide could be a direct one when smokers became inflicted with morbidity, but it could also be an indirect one, ${ }^{15}$ through the mechanism of depression, as smoking is associated with depression ${ }^{45} 46$ and depression is associated with suicide. ${ }^{43}$ This conclusion has been questioned..$^{44}$

Smoking in Taiwan is mainly a male behaviour and the increased injury risk has been limited to males in this study. The smoking or drinking status was self reported at the time of recruitment and may introduce recall/reporting bias. This potential bias cannot be quantified based on data collected for this study. Drinkers in this study were defined as those who admitted in the questionnaire to be a regular alcohol user, in contrast to an occasional or party drinker. Due to the lack of detailed drinking data (for example, number of drinks per week) among some cohort members, a more precise quantitative analysis of alcohol use cannot be made. We conducted only one to two surveys at the intake and not afterwards, so smoking and drinking behaviours may have changed over time. This may lead to a non-differential misclassification of smoking and drinking status. However, it is important to note that most of the cohort members were adults over 25 years of age, when non-smokers becoming new smokers are rare, accounting for only $1.2 \%{ }^{48}$ As a result, there would be more smokers who quit afterwards than nonsmokers who became smokers. The fact that we included these ex-smokers in our cohort as smokers would probably underestimate the mortality risk. However, the quit rate among smokers in Taiwan has been relatively small, with the cumulative lifetime ex-smoker amounting to one seventh of the smokers. ${ }^{23}$ Thus, the impact of the misclassification is likely to be small. Another limitation of this study is that only fatal injuries were included. Presumably, for every fatal injury, there were many more injuries that were not fatal, and thus the true burden of injury from smokers has been grossly underestimated in this study because only mortality was considered.

In summary, smokers in Taiwan have been at increased risk of mortality from accidental injuries of all types, and this risk increase is dose dependent. Smoking was associated with at least one out of every five male injury deaths in Taiwan. Quitting smoking would reduce these risks. Through accidents, the hazards of smoking are not limited to smokers themselves but affect smokers and non-smokers alike. That smokers exhibit such a high liability has not been publicised to smokers or non-smokers.

\section{Authors' affiliations}

C P Wen, T Y Cheng, H T Chan, W S I Chung, Division of Health Policy Research, National Health Research Institutes, Taipei, Taiwan

S P Tsai, The University of Texas Health Science Center at Houston, School of Public Health, Houston, Texas, USA

C J Chen, Graduate Institute of Epidemiology, College of Public Health, National Taiwan University, Taipei, Taiwan

Competing interests: none declared

\section{REFERENCES}

1 Thun M, Day-Lally C, Myers D, et al. Trends in tobacco smoking and mortality from cigarette use in cancer prevention studies I (1959 through 1965) and II (1982 through 1988). In: Burns DM, Garfinkel L, Samet JM, eds. Changes in cigarette-related disease risks and their implication for prevention and control. National Cancer Institute Monograph 8. Bethesda, Maryland, 1997: 305-82 (NIH Publication No.97-4213).

2 US Department of Health and Human Services. Reducing the health consequences of smoking: 25 years of progress. A report of the Surgeon General, 1989. Rockville, Maryland: Public Health Service, Centers for Disease Control, Office on Smoking and Health, 1989 (DHHS Publication No (CDC) 89-8411.).

3 US Department of Health and Human Services. Reducing tobacco use: a report of the Surgeon General. Atlanta, Georgia: US Department of Health and Human Services, Centers for Disease Control and Prevention, National Center for Chronic Disease Prevention and Health Promotion, Office on Smoking and Health, 2000

4 Peto R, Lopez AD, Boreham J, et al. Mortality from smoking worldwide. $\mathrm{Br}$ Med Bull 1996;52:12-21.

5 Center for Disease Control and Prevention. Annual smoking-attributable mortality, years of potential life lost, and economic costs - United States, 1995-1999. MMWR Morb Mortal Wkly Rep 2002;51:300-3.

6 Tsai SP, Cowles SR, Ross CE. Smoking and morbidity frequency in a working population. J Occup Med 1990;32:245-9.

7 Ryan J, Zwerling C, Orav EJ. Occupational risks associated with cigarette smoking: a prospective study. Am J Public Health 1992;82:29-32.

8 Tverdal A, Thelle D, Stensvold I, et al. Mortality in relation to smoking history: 13 years' follow-up of 68,000 Norwegian men and women $35-49$ years. J Clin Epidemiol 1993;46:475-87.

9 Doll R, Peto R, Weatley K, et al. Mortality in relation to smoking: 40 years' observations on male British doctors. BMJ 1994;309:901-11.

10 Kawachi I, Colditz GA, Stampfer MJ, et al. Smoking cessation in relation to total mortality rates in women. A prospective cohort study. Ann Intern Med 1993;119:992-1000.

11 Rogot E, Murray JL. Smoking and causes of death among U.S. veterans: 16 years of observation, Public Health Rep 1980;95:213-22.

12 Ross RK, Bernstein L, Trent L, et al. A prospective study of risk factors for traumatic deaths in a retirement community. Prev Med 1990;19:323-34.

13 Kaufman KR, Brodine S, Shaffer R. Military training-related injuries: surveillance, research, and prevention. Am J Prev Med 2000; 18(suppl 3):54-63.

14 Friedman GD, Tekawa I, Sadler M, et al. Smoking and mortality: the Kaiser Permanente experience. In: Burns DM, Garfinkel L, Samet JM, eds. Changes in cigarette-related disease risks and their implication for prevention and control.National Cancer Institute Monograph 8. Bethesda, Maryland: National Cancer Institute, 1997, 477-99 (NIH Publication No.97-4213).

15 Sacks JJ, Nelson DE. Smoking and injuries: an overview. Prev Med 1994;23:515-20.

16 Leistikow BN, Martin DC, Jacobs J, et al. Smoking as a risk factor for injury death: a meta-analysis of cohort studies. Prev Med 1998;27:871-8.

17 Leistikow BN, Martin DC, Samuels SJ. Injury death excesses in smokers: a 1990-95 United States national cohort study. Injury Prev 2000;6:277-80.

18 Ho MS. A long-term follow-up study of chronic diseases among civil servant and teachers in Taiwan. The Project Report. Taipei, Taiwan: Institute of Biomedical Sciences, Academia Sinica, 1993.

19 Liaw KM, Chen CJ. Mortality attributable to cigarette smoking in Taiwan: a 12-year follow-up study. Tobacco Control 1998;7:141-8.

20 Wen CP, Tsai SP, Chen CJ, et al. The mortality risks of smokers in Taiwan part I: cause-specific mortality. Prev Med 2004;39:528-35.

21 Yang MJ. The Chinese drinking problem: a review of the literature and its implication in a cross-cultural study. Kaohsiung J Med Sci 2002;18:543-50.

22 Shultz JM, Novotny TE, Rice DP. Quantifying the disease impact of cigarette smoking with SAMMEC II software. Public Health Rep 1991;106:326-33.

23 Cheng TY, Wen CP, Tsai MC, et al. The current status of smoking behavior in Taiwan: Data analysis from National Health Interview Survey in 2001 [in Chinese]. Taiwan J Public Health 2003;22:453-64.

24 Department of Health. Vital statistics in Taiwan. Taipei, Taiwan: Department of Health (DOH), Executive Yuan, Taiwan, 2002.

25 Tyndale RF. Genetics of alcohol and tobacco use in humans. Ann Med 2003;35:94-121.

26 Bien TH, Burge R. Smoking and drinking: a review of the literature. Int J Addict 1990;25:1429-54. 
27 Watkins SS, Koob GF, Markou A. Neural mechanisms underlying nicotine addiction: acute positive reinforcement and withdrawal. Nicotine Tob Res 2000;2:19-37.

28 Waters AJ, Jarvis MJ, Sutton SR. Nicotine withdrawal and accident rates. Nature 1998;394:137.

29 Sommese T, Patterson JC. Acute effects of cigarette smoking withdrawal: a review of the literature. Aviat Space Environ Med 1995;66:164-7.

30 Brison RJ. Risk of automobile accidents in cigarette smokers. Can J Public Health 1990;81:102-6.

31 Difranza JR, Winters TH, Goldberg RJ, et al. The relationship of smoking to motor vehicle accidents and traffic violations. NY State J Med 1986:86:464-7.

32 Grout $\mathrm{P}$, Cliff KS, Harman ML, et al. Cigarette smoking, road traffic accidents and seat belt usage. Public Health 1983;97:95-101.

33 National Institute for Occupational Safety and Health. Adverse health effects of smoking and the occupational environment, NIOSH Current Intelligence Bulletin No.31. Cincinnati, Ohio: National Institute for Occupational Safety and Health (NIOSH), 1979.

34 Department of Statistics, Ministry of Transportation and Communications. The users of mortorcycle by gender. In: The brief statistics of transportation \& communications by gender. http://www.motc.gov.tw/en/ hypage.cgi?HYPAGE = eng_stat.asp (Accessed 4 Oct 2004)

35 Ding S, Wang J, Chen K. Estimation of case fatality rate and incident rate of traffic injury in Taiwan - analysis of 4,329 victims at a medical center. J Formosan Med Assoc 1993;92:S76-81.

36 Moller A, Villebro N, Pedersen T. Interventions for preoperative smoking cessation. Cochrane Database Systematic Review 2001;4:CD002294.

37 Patton D, Barnes GE, RP M. A personality typology of smokers. Addict Behav 1997;22:269-73
38 Tsai SP, Gilstrap EL, Cowles SR, et al. Personal and job characteristics of musculoskeletal injuries in an industrial population. $J$ Occup Med 1992;34:606-12.

39 Leistikow BN, Shipley MJ. Might stopping smoking reduce injury death risks? A meta-analysis of randomized, controlled trials. Prev Med 1999:28:255-9.

40 Parrott AC. Smoking cessation leads to reduced stress, but why? Int J Addict 1995;30:1509-16.

41 US Department of Health and Human Services. The health benefits of smoking cessation. A report of the Surgeon General, 1990. Rockville, Maryland: Public Health Service, Centers for Disease Control, Office on Smoking and Health, 1990 (DHHS Publication No (CDC) 90-8416.).

42 Moller AM, Villebro N, Pedersen T, et al. Effect of preoperative smoking intervention on post operative complications: a randomised clinical trial. Lancet 2002;359:114-7.

43 Moscicki EK. Epidemiology of suicidal behavior. Suicide Life Threat Behav 1995;25:22-35.

44 Smith GD, Phillips AN, Neaton JD. Smoking as "independent" risk factor for suicide:illustration of an artifact from observational epidemiology? Lancet 1992:340:709-12.

45 Covey LS, Glassman AH, Stetner F. Cigarette smoking and major depression. $J$ Addict Dis 1998;17:35-46.

46 Glassman AH, Helzer JE, Covey LS, et al. Smoking, smoking cessation, and major depression. JAMA 1990;264:1546-9.

47 Hemmingson T, Kriebel D. Smoking at age 18-20 and suicide during 26 years of follow-up - how can the association be explained? Int J Epidemiol 2003;32:1000-5.

48 Bureau of Health Promotion and National Health Research Institutes. National Health Interview Survey (NHIS) in 2001 [in Chinese]. Bureau of Health Promotion and National Health Research Institutes, 2002. http:// nhis.nhri.org.tw (Accessed 5 July 2004).

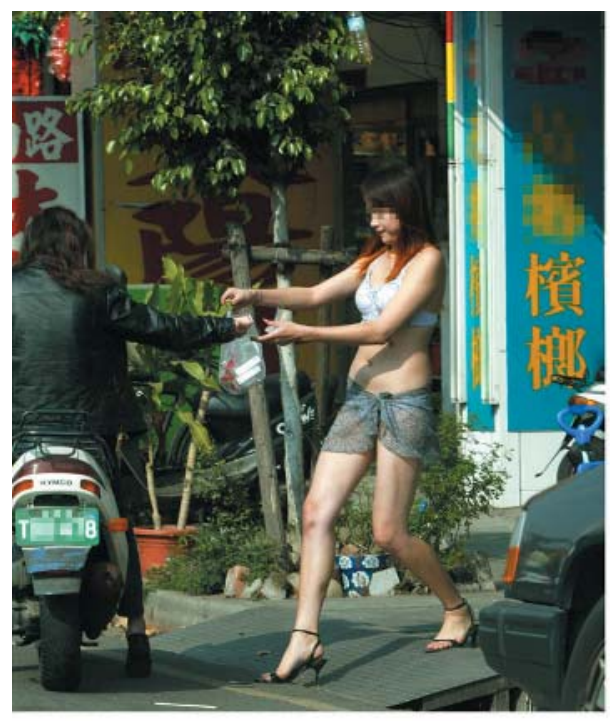

Catering betel quid and cigarettes to motorcyclists by Betel Quid Barbie

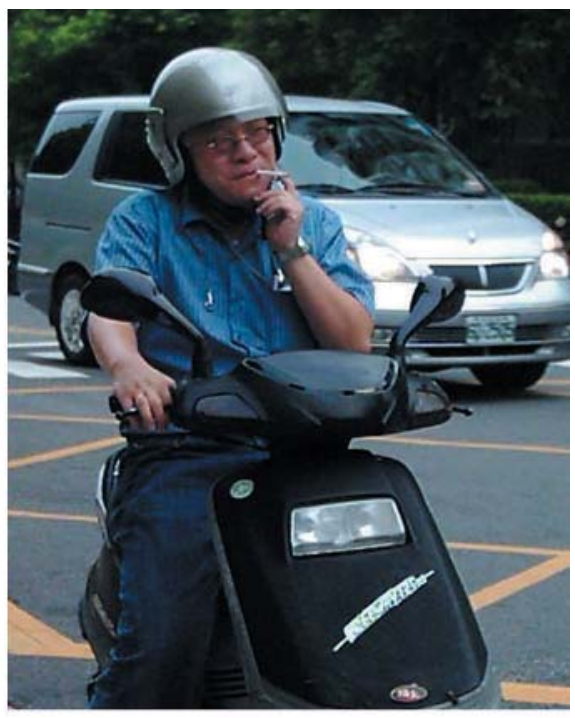

Smoking motorcyclists are prone for accidents 